\title{
Tedarikçilerin TOPSIS ile Seçilmesi ve Gelişim Durumlarının Sezgisel Optimizasyon ile Belirlenmesi*
}

\author{
Selecting the Suppliers with TOPSIS and Determining Their \\ Development Status by Using Heuristic Optimization
}

\author{
Ceylan Oğuz ${ }^{1}$ (D) İhsan Pençe ${ }^{2}$ (D, Melike Şişeci Çeşmeli ${ }^{\circledR}$, Özlem Çetinkaya Bozkurt ${ }^{4}$ (I)
}

"Bu çalışma 9-11 Aralık 2020 tarihlerinde gerçekleștirilen 7. Uluslararası Yönetim Bilişim bildirinin genișletilmiș halidir.

${ }^{1}$ (Yüksek Lisans Öğrencisi), Burdur Mehmet Akif Unniversitesi, Bucak Zeliha Tolunay Uygulamal ${ }_{1}$ Universitesi, Bucak Zeliha Tolunay Uygulamalı
Teknoloji ve İsletmecilik Yüksekokulu, Yönetim Bilișim Sistemleri Yüksek Lisans Programı, Bilişim Sistemle
Burdur, Türkiye

${ }^{2}$ (Dr. Öğr. Üyesi), Burdur Mehmet Akif Ersoy Üniversitesi, Bucak Teknoloji Fakültesi, Yazılım Mühendisliği Bölümü, Burdur, Türkiye

${ }_{3}^{3}$ Dr. Öğr. Üyesi), Burdur Mehmet Akif Ersoy Universitesi, Bucak Teknoloji Fakültesi, Yazılım Mühendisliği Bölümü, Burdur, Türkiye

${ }^{4}$ (Prof. Dr.), Burdur Mehmet Akif Ersoy Unniversitesi, Bucak İșletme Fakültesi, İşletme Bölümü, Burdur, Türkiye

ORCID: C.O. 0000-0002-1073-0766; I.P. $0000-0003-0734-3869$.

M.Ş.C. 0000-0001-9541-2590;

Ö.C.B. 0000-0002-6218-2570

\section{Corresponding author:}

Ceylan OGUZ
Burdur Mehmet Akif Üniversitesi, Bucak Zeliha

Tolunay Uygulamalı Teknoloji ve İșletmecilik

Yüksekokulu, Yönetim Bilișim Sistemleri Yüksek

Lisans Programı, Burdur, Türkiye

E-mail address: ceylanoguz070@gmail.com

Submitted: 26.01 .2021

Revision Requested: 17.02.2021

Last Revision Received: 30.03.202

Accepted: 02.04.202

Published Online: 31.05.2021

Citation: Oğuz, C., Pence, I., Siseci Cesmeli, M. ve Cetinkaya Bozkurt, O. (2021). Tedarikçilerin TOPSIS ile Seçilmesi ve gelişim durumlarının sezgisel optimizasyon ile belirlenmesi.

Acta Infologica, 5(1), 53-64.

https://doi.org/10.26650/acin 868427
ÖZ

Küreselleşmenin etkisiyle Türkiye'de üretim yapan işletmelerin sayısı gün geçtikçe artmaktadır. Bu durum perakende satış yapan işletmelerin seçebileceği tedarikçi sayısında artışlara neden olmaktadır. Ancak bazı işletmeler bulunduğu bölgede satışını yaptıkları ürünün markası ile tanındıkları için tedarikçi değişikliğinden kaçınmaktadır. İlgili markanın tedarikçisi ile arasındaki işbirliği bozulursa işletmenin satışlarında da düşüşler yaşanabilmekte olup, tedarikçi değiş̧ikliğine sıcak bakılmamaktadır. İşletme tedarikçisini değiştiremediği için tedarikçisinin kendisini geliştirmesini istemektedir. Bu çalışmada Burdur ilinde ev tekstili ürünleri satışı yapan bir işletme ele alınarak, işletmenin işbirliği yaptığı tedarikçiler arasından en iyisinin belirlenmesi ve diğer tedarikçilerin de kendilerini ne ölçüde geliştirmesi gerektiği problemi üzerinde durulmuştur. Analitik Hiyerarşi Süreci ve TOPSIS kullanılarak en iyi tedarikçi belirlendikten sonra diğer tedarikçilerin hangi ölçüde kendilerini geliştirmeleri gerektiği ise sezgisel optimizasyon ile belirlenmiştir. Toplamdaki 11 kriter belirlenirken 8 adet tedarikçi firma görüşü ile birlikte literatürden de yararlanılmıştır. Çalışmanın sonucunda ağırlı̆̆ı en yüksek olan kriter “ürünün kalitesi” olarak belirlenirken en iyi tedarikçinin tespiti ve diğer tedarikçilerin optimum durumu da başarı ile tespit edilebilmiştir.

Anahtar kelimeler: Analitik Hiyerarşi Süreci, TOPSIS, Sezgisel Optimizasyon, Tedarikçi İyileştirmesi

\begin{abstract}
The number of enterprises engaged in production in Turkey is increasing day by day with the impact of globalization. This situation causes an increase in the number of suppliers that retailers can choose. However, some businesses avoid changing suppliers because they are known for the brand of the product they sell in their region. If cooperation between the suppliers of the relevant brand is disrupted, the enterprise's sales may also decrease and the change of the supplier is not looked upon favorably. Since the business cannot change its supplier, it requests that its supplier improve itself. In this study, which focuses on an enterprise selling home textile products in the province of Burdur, the problems of determining the best among the suppliers with which the enterprise cooperates and the extent to which other suppliers should improve themselves are emphasized. After determining the best supplier using the Analytical Hierarchy Process and TOPSIS, the extent to which other suppliers should improve themselves is determined by heuristic optimization. The literature and the opinions of eight suppliers are used to determine $11 \mathrm{criteria}$ in total. As a result of the study, while the criterion with the highest weight is determined to be "quality of the product," the determination of the best supplier and the optimum status of other suppliers are also successfully determined.
\end{abstract}

Keywords: Analytical Hierarchy Process, TOPSIS, Heuristic Optimization, Supplier Improvement 


\section{GİRİŞ}

Tekstil ürünleri insanoğlunun varoluşundan itibaren önemli bir ihtiyaç olmuştur. Eski zamanlara bakıldığında tekstil giyim olarak başlangıç gösterir ancak zamanla değişen ihtiyaçlar doğrultusunda ev tekstili alanı oluşmuştur. Ev tekstilinde farklı özelliklerde ve çok sayıda ürün olması ve müşterilerin markalaşmış ürünleri tercih etmesi sebebiyle satıcının tedarikçi seçiminde zorlandığı durumlar ortaya çıkmaktadır. Tedarikçi seçimi bir işletme için karar verilmesi zor olan konulardan bir tanesidir. Eğer işletme tedarikçi seçiminde hata yaparsa bunun sonucunda satışlarda azalma, kâr oranında düşüşler, müşteri memnuniyetinde azalış ve maliyetlerde artış olma olasılığı oldukça yüksektir. Tedarikçi seçim problemi gerekli olan ürün veya hizmetleri sağlayabilecek kapasitede olan tedarikçiler arasından hangilerinin seçileceği sorunudur (Özdemir, 2007). Günümüzde firmalar ile tedarikçileri arasındaki ilişkiler değişmiş olup, artık alıcı ile satıcı firmalar aralarındaki ilişkileri güçlendirme yolunda ilerlemektedir. Tedarikçi seçimine etki eden kriterler alıcı ve satıcı arasındaki ilişkinin kazan-kaybet modelinden kazan-kazan modeline dönüşmesine katkıda bulunmaktadır (Vatansever, 2013). Bu noktada da işletmeyi en uygun tedarikçi veya optimum sonuca yönlendirecek AHP (Analitik Hiyerarşi Süreci), TOPSIS (Technique for Order Preference by Similarity to Ideal Solution) ve optimizasyon gibi çözümler gerekmektedir.

Günümüzde tedarikçi seçimi konusu, son yıllarda kapsamlı bir şekilde incelenmekte olan popüler bir sorun haline gelmiştir. Chai vd., (2013) karar verme tekniklerine dayalı olarak 2008-2012 yılları arasında yayınlanan tedarikçi seçim problemi hakkında 123 makaleyi inceledikten sonra tedarikçileri seçmek için kullanılan metodolojileri üç grupta sınıflandırmışlardır. İncelenen bu makalelere göre tedarikçi seçimi konusunda kullanılan yöntemlerin başında \% 44,4 ile AHP, ANP (Analitik Ağ Süreci) ve TOPSIS yöntemlerinin geldiği görülmektedir. Dolayısıyla literatürde tedarikçi seçiminde AHP ve TOPSIS yöntemlerinin birlikte kullanıldığı pek çok çalışma bulunmaktadır. Örneğin Wang vd., (2009), tedarikçi seçimi probleminde bulanık AHP ve TOPSIS yöntemlerini birlikte kullanmışlardır. Benzer şekilde Fazlollahtabar vd., (2011), araştırmalarında tedarikçi seçiminde AHP, TOPSIS ve çok amaçlı lineer olmayan programlamayı kullandıkları görülmektedir. Pramanik vd., (2017) makalelerinde, esnek bir tedarikçi seçme süreci geliştirmek için bulanık-çok kriterli bir grup karar verme yaklaşımı tasarlanmışlardır. Önerilen yöntemde, mesafe tabanlı optimizasyon metodolojisi, yani bulanık sistem ile entegre TOPSIS genel seçim kriterlerinin özelliklerini belirlemektedir. Benzer şekilde Günay ve Ünal (2016) telekomünikasyon sektöründeki bir firmayı ele almışlardır. Literatür taramasından ve uzman görüşlerinden yararlanarak belirlenen kriterleri AHP yöntemi ile önem derecesine göre sıralayıp, TOPSIS yöntemi ile de dört tedarikçi firmadan en uygun olanı belirlemişlerdir. Ağırlığ 1 en yüksek olan kriter 'ürün kalitesi’ kriteri olarak belirlenmiştir. Özçakar ve Demir (2011) ise bir gıda işletmesindeki karar vericilerle yapılan mülakatlar sonucunda edinilen bilgilerden yararlanarak yapılacak tedarikçi seçimini bulanık TOPSIS yöntemiyle gerçekleştirmişlerdir. Supçiller ve Çapraz (2011) bir işletmenin tedarikçi seçimini AHP-TOPSIS yöntemleriyle yapabilmesi için model önermişlerdir. Önerilen modelde TOPSIS yöntemi ile tedarikçiler sıralanmış ve en iyi tedarikçi belirlenmiştir. Tedarikçilerin değerlendirilmesinde kullanılan kriterlerden kalite, fiyat, teslimat ve hizmet kriterleri ana kriterler olarak belirlenmiştir. İlgili çalışmada önem derecesi en yüksek kriter olarak ‘ürünün kalitesi’ kriteri belirlenmiştir. Vatansever (2013) tekstil sektöründe çalışan büyük işletmelere fason üretim yapan bir firmanın tedarikçi seçimini Bulanık TOPSIS yöntemiyle değerlendirmiştir. Öztürk (2019) Ordu ili Organize Sanayi Bölgesinde bulunan bir hazır giyim işletmesinin en uygun kumaş hammadde tedarikçisi seçiminde AHP-TOPSIS yöntemlerini kullanmıştır. Okwu ve Tartibu (2020) perakende sektöründe sürdürülebilir tedarikçi seçimi probleminin çözümü için TOPSIS ve ANFIS (Adaptive Neuro-Fuzzy Inference Systems) yöntemi kullanmışlardır. Avcı ve Çınaroğlu (2018), 5 havayolu firmasının 4 yıllık süre içerisinde göstermiş oldukları finansal performansları AHP ve TOPSIS yöntemlerini kullanarak sıralamışlardır. Şahin ve Akyer (2011) ise çalışmalarında kamu kurumlarında kullanılmak için alınacak olan 4×4 arama kurtarma aracı seçimi için AHP ve TOPSIS yöntemlerini kullanmışlardır. Literatürde sezgisel optimizasyon yöntemi ile ilgili çalışmalar da yapılmıştır. Akbel ve Kahraman (2020), çalışmalarında çok amaçlı sezgisel optimizasyon algoritmalarını test etmek için bir platform tasarlamışlardır. Literatürde bulunan 8 tane meta-sezgisel optimizasyon algoritmasından faydalanarak 24 tane birbirinden farklı problem üzerinde performans değerleri ölçülmüş ve performans karşılaştırmaları yapılmıştır. Kaya Keleş ve Keleş (2017) ise çalışmalarında literatürde son 5 yılda inşaat sektörünün temeli olan yapım yönetimi konusunda veri madenciliği ve sezgisel optimizasyon algoritmaları ile ilgili çalışmaları inceleyip ayrıntılı olarak tablo üzerinde kronolojik olarak göstermişlerdir. Niranjan vd., (2021), çalışmalarında farklı talep senaryolarında çoklu ürün akışı için yeşil tedarikçi seçimi ve sipariş tahsisi için bir model 
önerip ilgili problemi yeni bir meta-sezgisel algoritma kullanarak çözüm getirmişlerdir. Özçelik ve Gündüz (2019) araştırmalarında bir otomobil fabrikasında otomobil montajında kullanılan parçaların raflardaki yerleşimini optimum şekilde kullanılmasını sağlayacak sezgisel algoritmalar kullanarak en iyiye yakın raf yerleştirme işlemini gerçekleştirilmiştir. Fırat ve Alpaslan (2019) ise bir işletmede üretim sürecindeki kesme ve paketleme sorununa ilişkin alt sol dolgu, ilk uygun azalan ve uygun olmayan çokgen sezgisel algoritmaları kullanarak iki boyutlu dikdörtgen şerit paketleme problemine çözüm sunulmaya çalışılmışıtır. Tempelmeier (2002) araştırmasında endüstriyel satın alma uygulamasıyla ilgili varsayımlar altında dinamik sipariş boyutlandırma ve tedarikçi seçimi problemi için yeni model formülasyonları ve sezgisel bir çözüm yöntemi geliştirmiştir.

Görüldüğü üzere literatürde AHP ve TOPSIS yöntemlerinin tedarikçi seçimi probleminin çözümü için oldukça yaygın bir şekilde kullanıldıkları görülmektedir. Ancak AHP ve TOPSIS ile tedarikçi seçimi yapılan çalışmalarda tedarikçilerin birbirleri ile durumları hakkında bir değerlendirme yapılmayıp sadece en iyi tedarikçinin belirlenmesine odaklanılmıştır. $\mathrm{Bu}$ durum tedarikçilerin işletmeler için nasıl tercih edilebilir olabilecekleri ile ilgili öneriler sunmamaktadır. Bu çalışmada ise literatürde yer alan diğer çalışmalardan farklı olarak AHP ve TOPSIS yöntemleri ile en iyi tedarikçi belirlendikten sonra diğer tedarikçilerin kendilerini en iyi tedarikçiye göre ne ölçüde geliştirmeleri gerektiği problemi sezgisel optimizasyon kullanılarak gerçekleştirilmiştir. Bunun yanında tedarikçilerin birbirleri ile kıyaslamalarının yapılması ve araştırmanın ev tekstili sektöründe olması da ilgili çalışmayı diğer çalışmalardan farklı kılmaktadır. Sonuç olarak araştırmada, Burdur ilinde ev tekstil ürünleri satışı yapan bir firmanın tedarikçi seçimi sorunu ele alınmıştır. Amaç işletmenin çalıştığı tedarikçileri arasından en iyiyi belirleyip diğer tedarikçileri de en iyi tedarikçi olma yolunda yönlendirerek hem tedarikçilere hem de işletmeye fayda sağlayacak adımlar atılmasını sağlamaktır. İşletmenin tedarikçi seçiminde işletme sahibi ile görüşülüp tedarikçi seçiminde kullanılan kriterler belirlenip derecelendirilmiştir. Kriterler ve ağırlıklar belirlendikten sonra en uygun değer durum ise sezgisel optimizasyon ile tespit edilmiştir.

\section{YÖNTEM}

$\mathrm{Bu}$ çalışmada en uygun tedarikçinin belirlenmesinde çok kriterli karar verme modellerinden olup, kriter ağırlıklandırma da kullanılan AHP ve sıralama yapılırken kullanılan TOPSIS yöntemlerinden faydalanılırken, optimum kriter ve değerlerin belirlenmesi ise sezgisel bir yöntem olan Kümeleme Tabanlı Global Optimizasyon (KTGO) ile gerçekleştirilmiştir.

\subsection{Analitik Hiyerarşi Süreci}

Thomas L. Saatly (1980) tarafindan geliştirilen ve çok kriterli karar verme yöntemlerinden biri olan AHP matematiksel bir yöntemdir. Bu yöntemin tercih edilmesindeki en büyük etken birden çok kriterin önem düzeylerinin belirlenmesine olanak sağlamasıdır (Saatly ve Özdemir, 2003). AHP karar veren kişilere öznel değerlendirmeleri nicel kriterlere dönüştürme firsatı sunar.

AHP yönteminin ilk adımında modelin belirlenmesi işlemi bulunmakta olup, bu adım karar vericinin amacına yönelik kriterlerin, alt kriterlerin ve alternatiflerin belirlenmesi sürecini içermektedir. Alınacak olan kararın hatasız olması için belirlenen kriterler iyi seçilmelidir (Pençe vd., 2017). İkinci adımda, ikili karşılaştırma matrisinin oluşturulması aşaması bulunmakta olup belirlenmiş kriterler ve alternatifler kullanılarak kriterler ve alternatiflerin ikili karşılaştırma matrisleri 1-9 önem skalası ile oluşturulur. Üçüncü adımda ise, kriterlerin öz vektörlerinin hesaplanması aşaması yer alıp karar vericilerin tecrübeleri ile belirledikleri matriste yer alan kriterlere göre önem derecesini ifade eden öz vektör hesabı gerçekleştirilmektedir (Supçiller ve Çapraz, 2011). Dördüncü adımda, ikili karşılaştırmalarda kıyaslama yapılırken tutarlılık oranlarının hesaplanması yer almakta olup, tutarlılık oranının 0.10 değerinden küçük olması gerekmektedir. Bu oranın 0.10 değerinden daha büyük olması ya AHP'deki bir hesaplama hatasını ya da karar vericinin ikili karşılaştırmalarının tutarlı olmadığı anlamına gelmektedir (Saaty, 1980). Beşinci ve son adım ise, sonuç ağırlıkları bulunup genel alternatifler ile sıralama yapılmaktadır. İkili karşılaştırmalar matrisinde bulunan değerler birleştirilerek en alt seviyedeki alternatiflerin sonuç ağırlıkları bulunur. Elde edilen sonuçların sıralanmasıyla karar verici en iyi alternatifi seçebilir (Kerkhoff, 2018). 


\subsection{TOPSIS Yöntemi}

TOPSIS yöntemi 1981'de Hwang ve Yoon tarafından geliştirilmiş olan çok kriterli karar verme yöntemlerinden biridir. Bu yöntem pozitif-ideal çözüme en yakın mesafedeki ve negatif-ideal çözüme en uzak mesafedeki alternatifleri bulmaya çalışır Shyjith vd., 2008). TOPSIS yönteminin uygulama adımları şu şekildedir;

1. adım: karar matrisinin oluşturulması:

TOPSIS yönteminin ilk adımı, kriterlerin belirlenmesi ve sonrasında karar matrisinin oluşturulmasıdır. Karar matrisinin sütununda karar vermede kullanılacak değerlendirme faktörleri, satırında ise üstünlükleri sıralanmak istenen alternatifler yer almaktadır. Denklem (1)'de karar matrisini ifade eden $A$ gösterilmektedir (Dumanoğlu ve Ergül, 2010).

$$
A_{i j}=\left[\begin{array}{cccc}
a_{11} & a_{12} & \ldots & a_{1 n} \\
a_{21} & a_{22} & \ldots & a_{2 n} \\
\vdots & & & \vdots \\
a_{m 1} & a_{m 2} & \ldots & a_{m n}
\end{array}\right]
$$

2. adım: karar matrisinin normalleştirilmesi:

Oluşturulmuş olan karar matrisinin verilerinden yararlanılarak sütundaki her bir değer aynı sütundaki değerlerin kareleri toplamının kareköküne bölünmesiyle normalleştirme işlemi Denklem (2)'ye göre gerçekleştirilmektedir (Yayar ve Baykara, 2012).

$$
r_{i j}=\frac{a_{i j}}{\sqrt{\sum_{i=1}^{m} a_{i j}^{2}}}
$$

Denklem (2)'de yer alan i; 1.2.3...n kriter sayısını ifade ederken, j; 1.2.3 ....m ise alternatif sayısını göstermektedir.

3. adım: normalize edilmiş karar matrisinin oluşturulması:

İlk olarak değerlendirme faktörlerine bağlı ağırlık değerleri hesaplanır, sonrasında ise ikinci adımda oluşturulan matrisin her bir sütunundaki elemanlar bulunan ağırlık değeriyle çarpılarak normalize edilmiş karar matrisini ifade eden $V$, Denklem (3)'teki gibi belirlenir (Yayar ve Baykara, 2012).

$$
V_{i j}=\left[\begin{array}{cccc}
v_{1} r_{11} & v_{2} r_{12} & \ldots & v_{n} r_{1 n} \\
v_{1} r_{21} & v_{2} r_{22} & \ldots & v_{n} r_{2 n} \\
\vdots & & & \vdots \\
v_{1} r_{m 1} & v_{2} r_{m 2} & \ldots & v_{n} r_{m n}
\end{array}\right]
$$

4. adım: pozitif ve negatif ideal çözümlerin oluşturulması:

İdeal çözüm, ağırlıklı normalleştirilmiş karar matrisinin en iyi performans değerlerinden oluşurken, negatif ideal çözüm ise, ağılıklı normalleştirilmiş karar matrisinin en kötü değerlerinden oluşmaktadır. İdeal çözümler Denklem (4)’teki gibi elde edilmektedir (Shyjith vd., 2008).

$$
\begin{aligned}
& A^{+}=\left\{\left(\max _{i} v_{i j} \mid j \in J\right),\left(\min _{i} v_{i j} \mid j \in J^{\prime}\right)\right\} \\
& A^{-}=\left\{\left(\min _{i} v_{i j} \mid j \in J\right),\left(\max _{i} v_{i j} \mid j \in J^{\prime}\right)\right\}
\end{aligned}
$$

5. adım: ayırım ölçülerinin hesaplanması:

$\mathrm{Bu}$ adımda alternatifler arasındaki ayırım hesaplanmaktadır. Pozitif ideal çözüm kümesinden sapma değeri hesaplanırken Denklem (5), negatif ideal çözüm kümesinden sapma değeri hesaplanırken ise Denklem (6) kullanılmaktadır (Ertuğrul ve Özçil, 2014).

$$
S_{i}^{+}=\sqrt{\sum_{j=1}^{n}\left(v_{i j}-v_{j}^{+}\right)^{2}}
$$




$$
S_{i}^{-}=\sqrt{\sum_{j=1}^{n}\left(v_{i j}-v_{j}^{-}\right)^{2}}
$$

6. adım: ideal çözüme göreli yakınlığın hesaplanması:

$\mathrm{Bu}$ adımda alternatiflerin ideal çözüme göreli yakınlığını ifade eden $\mathrm{C}_{\mathrm{i}}^{*}$ hesaplanmakta olup Denklem (7)' de verilmiştir. İlgili hesaplama yapılırken pozitif ve negatif ideal ayırım ölçülerinden faydalanılmaktadır. Negatif ideal ayırım ölçüsünün, toplam ayırım ölçüsü içindeki payı yakınlık katsayısı değerini vermektedir (Ertuğrul ve Özçil, 2014).

$$
C_{i}^{*}=\frac{s_{i}^{-}}{S_{i}^{-}+S_{i}^{+}}
$$

\subsection{Sezgisel Optimizasyon}

Optimizasyon, matematiksel olarak herhangi bir fonksiyonu veya problemi minimize veya maksimize etmektir. Optimizasyon temelinde her zaman en iyiye ulaşmayı amaçlamaktadır. Günümüze kadar farklı problemlerin çözümü için birçok optimizasyon yöntemi geliştirilmiştir (Çunkaş, 2004).

Yapay zekâ evrendeki varlıkların akıllı davranışlarını yapay olarak taklit eden bir süreç olup, bünyesinde kümeleme ve sınıflandırma problemleri için birçok algoritma barındırmaktadır (Atalay ve Çelik, 2017). Kümeleme analizi birbirine benzeyen verilerin aynı gruplarda olmasını sağlamaktadır (Çakmak vd., 2005). Kümeleme analizi veri madenciliğinin yanı sıra diğer alanlarda da kullanılmakta olup sezgisel optimizasyondaki kulanım alanında KTGO yöntemi ön plana çıkmaktadır. KTGO yöntemi popülasyon elemanlarını kümeleme işlemi sonucunda gruplayarak ilgili kümede yer alan elemanlara parabolik eğriler geçirmek suretiyle daha iyi noktalara ulaşmasıyla ön plana çıkan bir sezgisel optimizasyon yöntemidir (Pençe vd., 2016).

KTGO yönteminin en önemli adımlarından olan küme merkezlerinin belirlenmesi ve parabol uydurma işlemleri Şekil 1'de görülmektedir.

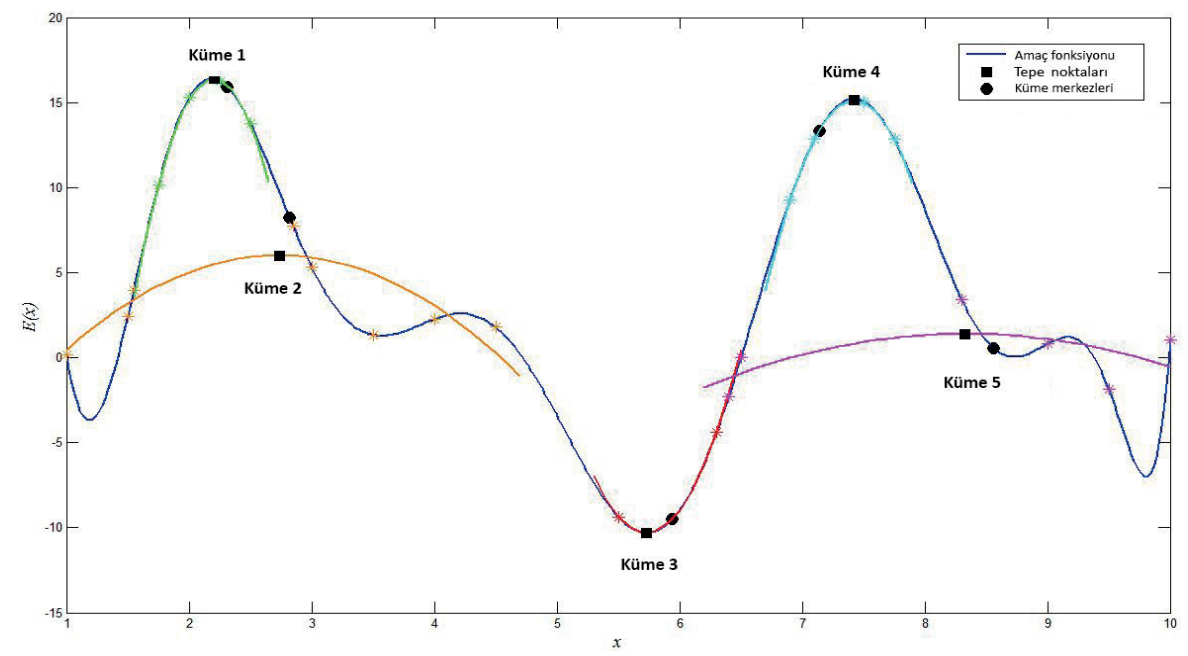

Şekil 1. KTGO yönteminin küme belirleme ve parabol uydurma işlemi (Pençe vd., 2016)

KTGO yöntemine ait algoritma ise aşağıda verilmiştir.

\section{KTGO Algoritması:}

1. Önceden belirlenen popülasyon büyüklüğüne göre ilk popülasyonu rastgele elemanlardan oluştur ve popülasyondaki her elemanın hata değerini hesapla.

2. Popülasyon-Hata oranı ve önceden belirlenen küme sayısına göre Bulanık C-Ortalamalar Kümeleme yöntemi ile kümeleme işlemi yap. 
3. Fonksiyon değerlerine göre kümeleri sırala ve küme sayısının 1/3 oranında en iyi kümeleri seç.

4. Seçilen her bir kümeye ait elemanları kullanarak her boyut için ayrı ayrı parabolik eğri uydurma gerçekleştir ve oluşan eğrilerin iç bükey veya dış bükey olduğunu tespit et.

5. İç bükey eğrilerde minimum nokta hata değerinden daha küçük ise küme merkezini bu minimum nokta ile değiştir. Diş bükey eğriler için ise küme merkezini değiştirmeden kullan.

6. Önceki popülasyonun en iyi elemanları ile birlikte küme merkezi etrafından rastgele seçilen yeni elemanlarla yeni popülasyonu oluştur. Çıkarılan kümelere ait bireyler yerine yeni noktalar ekle.

7. Yeni popülasyondaki eleman değerlerini önceden belirlenmişs sınırlarda tut.

8. Yeni popülasyondaki her eleman için hata değeri hesapla.

9. Hata değeri önceden belirlenen eşik değerinden küçükse veya hedeflenen tekrara erişilmişse algoritmayı sonlandır değilse 2. adıma git.

Literatürdeki diğer bazı yöntemlere kıyasla KTGO yöntemi hızlı yapısı ve global optimuma ulaşmadaki başarısı ile ön plana çıkmaktadır (Pençe vd., 2016).

\section{DENEYSEL ÇALIŞMALAR}

Araştırma Burdur ilinde ev tekstili ürünleri satışı yapan bir işletmede gerçekleştirilmiştir. İşletmede havlu, bornoz, battaniye, perde, yastık, yorgan, halı gibi çok fazla ürün çeşidi bulunmaktadır. Bundan dolayı da işletme çok sayıda tedarikçi ile işbirliği içindedir. Yıllardır aynı tedarikçilerle çalışan işletme sahibi, tedarikçi firmalarla arasındaki özel ilişkilerden ve işletmenin o tedarikçinin markası ile anılmasından dolayı tedarikçisini değiştirmek istememektedir. Bunun yerine tedarikçilerine kendilerini geliştirmeleri ve ilişkilerinin daha karlı olabilmesi için yol göstermektedir. İşletme sahibinin tedarikçilerini doğru yönlendirebilmesi için daha bilimsel kararlar vermesi gerekmektedir. Bu çalışmada kullanılan yöntemler işletme sahibinin fikrini daha nesnel olarak belirlemesine yardımcı olacak düzeydedir. Çalışmada işletmenin en çok mal aldığı tedarikçiler olan 8 firma incelenmiştir. Bu firmalar Firma A, Firma B, Firma C, Firma D, Firma E, Firma F, Firma G, Firma H olarak gösterilmiştir. Tedarikçi firmaları değerlendirmek ve matematiksel bir model ortaya koyabilmek için işletmenin sahibi ve yöneticisi pozisyonunda olan kişiler ile birlikte ilgili kriterler belirlenmiştir. Kriterler belirlenirken literatürden de faydalanılmıştır. Supçiller ve Çapraz (2011), çalışmalarında gerçekleştirdikleri literatür taraması sonucunda en uygun tedarikçinin değerlendirilmesi ve seçilmesi için karar vericiler tarafından düşünülen kriterleri araştırmışlardır. Buna göre en popüler kriterler sırasıyla kalite, fiyat, teslimat, servis, esneklik, teknoloji, teknik, uzaklık vb. olarak belirlenmiştir. Bu çalışmadaki kriterler belirlenirken de işletmenin sahibi ve yöneticisi pozisyonunda olan kişilere bu kriterlerin işletme için uygun olup olmadığı önerilmiş olup, bu kriterler ile işletmeye özgü kriterler birlikte değerlendirilip belirlenmiştir. Bu çalışmada yararlanılan kriterler ve açıklamaları Tablo 1'de gösterilmektedir.

Tablo 1

Kriterler ve açılamaları

\begin{tabular}{lcc}
\hline Kriter No & Kriter Adı & Kriter Açıklaması \\
\hline 1 & Ürün kalitesi (ÜK) & Alınan ürünün kalitesini göstermektedir. \\
2 & Defosuz ürün miktarı (DÜM) & Alınan ürünün ne kadarının defosuz olduğunu göstermektedir. \\
3 & Zamanında teslimat (ZT) & Teslimatın verilen süre içinde yapılıp yapılmadığını göstermektedir. \\
4 & Paketleme Yeteneği (PY) & Ürünün nasıl paketlendiğini göstermektedir. \\
5 & İletişim kolaylığı (İK) & Tedarikçi ile iletişimin nasıl olduğunu göstermektedir. \\
6 & Sorunlara yaklaşım (SY) & Tedarikçinin sorunlara yaklaşımını göstermektedir. \\
7 & Şikâyet politikaları (ŞP) & Tedarikçinin şikâyetler karşısında tutumunu göstermektedir \\
8 & Ürün-fiyat uygunluğu (ÜFU) & Ürünün satış fiyatına uygunluğunu göstermektedir. \\
9 & İskonto miktarı (İM) & Tedarikçinin sağladığı iskonto miktarını göstermektedir. \\
10 & Ödeme vadesi (ÖV) & Yapılan ödemelerin vadesini göstermektedir. \\
11 & Ödeme şekli (ÖŞ) & Yapılan ödemelerin şeklini (kredi nakit) göstermektedir. \\
\hline
\end{tabular}


Tablo 1'de yer alan kriterlerden [kriter no: 1-10] olanlar Supçiller ve Çapraz (2011)'a ait çalışmada belirlenen kriterleri oluştururken ÖŞ kriteri ise işletme yöneticileri tarafından önerilip çalışmaya dahil edilmiştir. Çalışmanın amacı Tablo 1'de verilen kriterlerden yararlanılarak tedarikçi firmalar içindeki en iyi firmayı belirleyip diğer firmaların da bu firmaya göre kendilerini ne yönde geliştirmeleri gerektiğini tespit etmektir. Bunun için ise en iyi firma AHP ve TOPSIS yöntemleri ile tespit edilmiş, sonrasında ise en optimum gelişim özellikleri sezgisel bir optimizasyon yöntemi olan KTGO ile belirlenmiştir. İlgili optimizasyon geliştirilen tedarikçi firmalar için rekabet dinamiği ele alınmamıştır.

\section{BULGULAR}

\subsection{AHP Yönteminin Uygulanması}

AHP'nin ilk aşaması olan karar matrisi oluşturma adımında Tablo l'de yer alan 11 adet kriter ve alternatifler kullanılmışır. Karşılaştırma matrisinin oluşturulması için bu kriterlerin önem derecelerinin belirlenmesi gerekmektedir. Bunun için Saaty (1980) tarafından geliştirilen 1-9 önem skalası ölçeği kullanılmıştır. Karşılaştırma matrisi Tablo 2'de verilmiştir.

Tablo 2

Kriterlerin karşılaştırma matrisi

\begin{tabular}{|c|c|c|c|c|c|c|c|c|c|c|c|}
\hline & ÜK & DÜM & ZT & PY & İK & SY & ŞP & ÜFU & İM & ÖV & ÖŞ \\
\hline ÜK & 1 & 3 & 4 & 5 & 6 & 6 & 6 & 3 & 4 & 5 & 5 \\
\hline DÜM & 0.33 & 1 & 3 & 4 & 5 & 5 & 5 & 1 & 3 & 4 & 4 \\
\hline ZT & 0.25 & 0.33 & 1 & 2 & 3 & 3 & 3 & 0.5 & 4 & 5 & 5 \\
\hline PY & 0.2 & 0.25 & 0.5 & 1 & 2 & 3 & 3 & 0.25 & 0.33 & 0.5 & 0.5 \\
\hline İK & 0.16 & 0.2 & 0.33 & 0.5 & 1 & 1 & 1 & 0.2 & 0.33 & 0.5 & 0.5 \\
\hline SY & 0.16 & 0.2 & 0.33 & 0.33 & 1 & 1 & 1 & 0.2 & 0.33 & 0.5 & 0.5 \\
\hline ŞP & 0.16 & 0.2 & 0.33 & 0.33 & 1 & 1 & 1 & 0.2 & 0.33 & 0.5 & 0.5 \\
\hline ÜFU & 0.33 & 1 & 2 & 4 & 5 & 5 & 5 & 1 & 0.5 & 0.33 & 0.33 \\
\hline İM & 0.25 & 0.33 & 0.25 & 3 & 3 & 3 & 3 & 2 & 1 & 2 & 2 \\
\hline ÖV & 0.2 & 0.25 & 0.2 & 2 & 2 & 2 & 2 & 3 & 0.5 & 1 & 1 \\
\hline ÖŞ & 0.2 & 0.25 & 0.2 & 2 & 2 & 2 & 2 & 3 & 0.5 & 1 & 1 \\
\hline
\end{tabular}

Karşılaştırma matrisinden sonra kriterlerin ağırlıklarının belirlenmesi için normalize edilmiş karşılaştırma matris oluşturulmuştur. Normalize karşılaştırma matrisi için her sütun değeri aynı sütunun değeri toplamına bölünürken, ağırlıkların belirlenmesi için de normalize edilmiş matrisin satır değerlerinin ortalaması alınır. Kriterlerin ağırlıkları Tablo 3'deki gibi elde edilmiştir. Ağırlıklar belirlendikten sonra tedarikçilerin sıralamalarının oluşturulması için TOPSIS yöntemi kullanılırken tedarikçilerin kendilerini iyileştirmeleri içinde yine bu ağırlıklardan yararlanılmıştır.

Tablo 3

Kriterlerin ă̆ırlıkları

\begin{tabular}{ccccccccccccc}
\hline Kriter & ÜK & DÜM & ZT & PY & İK & SY & ŞP & ÜFU & İM & ÖV & ÖŞ \\
\hline A ğırlık & 0.255 & 0.163 & 0.124 & 0.047 & 0.027 & 0.026 & 0.026 & 0.107 & 0.086 & 0.065 & 0.065
\end{tabular}

Tablo 3’te belirtilen kriterlerin ağırlıkları hesaplandıktan sonra tutarlılık analizi uygulanmıştır. Buna göre tutarlılık göstergesi 0.156 olarak hesaplanırken, bu değerin random gösterge değeri olan 1.51'e bölünmesiyle tutarlılık oranı 0.10 olarak elde edilmiştir. Tutarlılık oranı 0.10’dan büyük olmadığı için ağırlıklar tutarlı kabul edilerek TOPSIS ve KTGO için kullanılmıştır.

\subsection{TOPSIS Yönteminin Uygulanması}

AHP ile belirlenen alternatifler ve kriterler kullanılarak karar matrisi oluşturulmuştur. Oluşturulan karar matrisinin satırlarında alternatifler yani tedarikçi firmalar yer alırken sütunlarında ise belirlenen kriterler yer almaktadır. Tedarikçi firmaların değerlendirildiği karar matrisi Tablo 4’te gösterilmiştir. 
Tablo 4

Karar matrisi

\begin{tabular}{|c|c|c|c|c|c|c|c|c|c|c|c|}
\hline & ÜK & DÜM & $\mathbf{Z T}$ & PY & İK & SY & ŞP & ÜFU & İM & ÖV & ÖŞ \\
\hline $\mathbf{A}$ & 8 & 8 & 7 & 7 & 8 & 8 & 8 & 5 & 7 & 5 & 6 \\
\hline B & 8 & 7 & 7 & 8 & 7 & 7 & 7 & 7 & 5 & 6 & 6 \\
\hline C & 7 & 7 & 5 & 7 & 8 & 8 & 8 & 7 & 8 & 7 & 8 \\
\hline D & 9 & 8 & 8 & 8 & 8 & 8 & 7 & 4 & 6 & 4 & 5 \\
\hline $\mathbf{E}$ & 7 & 6 & 5 & 7 & 7 & 7 & 7 & 8 & 7 & 6 & 6 \\
\hline $\mathbf{F}$ & 8 & 8 & 5 & 7 & 8 & 8 & 8 & 7 & 7 & 6 & 6 \\
\hline $\mathbf{G}$ & 7 & 6 & 5 & 9 & 7 & 7 & 7 & 8 & 6 & 6 & 6 \\
\hline H & 8 & 7 & 7 & 7 & 8 & 8 & 8 & 7 & 7 & 6 & 8 \\
\hline
\end{tabular}

Tablo 4'te yer alan karar matrisinin normalleştirme işlemi ise sütundaki her bir değerin ilgili sütunun değerlerinin kareleri toplamının kareköküne bölünmesi ile yapılmaktadır. Elde edilen değerlerin, AHP ile Tablo 3’teki gibi tespit edilen kriter ağırlıkları ile çarpılması ile de ağırlıklandırılmış karar matrisi bulunmuştur. Son olarak ağırlıklar kullanılarak tedarikçi firmalar için göreli yakınlıklar Tablo 5’teki gibi elde edilmiştir.

Tablo 5

Göreli yakınlıklar

\begin{tabular}{lcccccccc}
\hline Firma & A & B & C & D & E & F & H \\
\hline Yakınlık & 0.52685 & 0.54295 & 0.44863 & 0.56199 & 0.40122 & 0.51681 & 0.39068 & 0.62103
\end{tabular}

Tablo 5'te de görüldüğü gibi, elde edilen sonuçlara göre en iyi firma H olarak belirlenmiş olup, bu firma optimizasyon için en optimum değer kabul edilip en az maliyetle diğer firmaların çabaları KTGO yöntemiyle optimize edilmeye çalışılmıştır.

\subsection{Optimizasyon Yönteminin Uygulanması}

KTGO yöntemi ile TOPSIS’te bulunan en iyi tedarikçiyi temel alarak diğer tedarikçilerin en iyiye olan uzaklığı bulunmuştur. Burada yer alan karar matrisinde ilgili kriterin alt ve üst sınırları kullanılmıştır. Bunun sebebi tedarikçilerin aynı kriteri dönem dönem farklı seviyelerde sağlayabilmeleridir. Kriterlerin etkinlik durumu mevsim değişikliklerinden, enflasyondan ve çalışanların davranışlarından etkilenebilmektedir. İskonto miktarı, teslimat zamanı ve ödeme vadesi gibi sık sık değişebilen kriterler için firmaları puanlandırmak çok doğru bir değerlendirme kriteri olarak düşünülmemektedir. Bu sebeple 1-9 önem ölçeği yerine işletme sahibinin kişisel görüşlerinden yararlanılarak alt ve üst sınırlar belirlenmiş ve Tablo 6'da gösterilmiştir.

Tablo 6

Optimizasyon karar matrisi

\begin{tabular}{|c|c|c|c|c|c|c|c|c|c|c|c|}
\hline & ÜK & DÜM & ZT & PY & İK & SY & ŞP & ÜFU & İM & ÖV & ÖŞ \\
\hline A & $7-9$ & $7-9$ & $7-8$ & $6-8$ & $8-9$ & $8-9$ & $7-9$ & $4-6$ & $6-8$ & $4-6$ & $5-7$ \\
\hline B & $7-9$ & $6-8$ & $7-8$ & $7-9$ & $6-8$ & $6-8$ & $6-8$ & $6-8$ & $4-6$ & $6-7$ & $5-7$ \\
\hline C & $6-8$ & $6-8$ & $4-6$ & $6-8$ & $8-9$ & $8-9$ & $7-9$ & $6-8$ & $7-9$ & $7-8$ & $7-9$ \\
\hline D & $8-10$ & $8-9$ & $7-9$ & $7-9$ & $8-9$ & $8-9$ & $6-8$ & $3-5$ & $5-7$ & $3-5$ & 4-6 \\
\hline $\mathbf{E}$ & $6-8$ & $5-7$ & $4-6$ & $6-8$ & $6-8$ & $6-8$ & $6-8$ & $7-9$ & $6-8$ & $6-7$ & $5-7$ \\
\hline $\mathbf{F}$ & $7-9$ & $7-9$ & $4-6$ & $6-8$ & $8-9$ & $8-9$ & $7-9$ & $6-8$ & $6-8$ & $6-7$ & $5-7$ \\
\hline G & $6-8$ & $5-7$ & $4-6$ & $7-9$ & $6-8$ & $6-8$ & $6-8$ & $7-9$ & $5-7$ & $6-7$ & $5-7$ \\
\hline H & $7-9$ & $6-8$ & $7-8$ & $6-8$ & $8-9$ & $8-9$ & $7-9$ & $6-8$ & $6-8$ & $6-7$ & $7-9$ \\
\hline
\end{tabular}

Tablo 6'da yer alan optimizasyon için oluşturulan karar matrisinden ve Tablo 3'te belirtilen kriter ağırlıklarından yararlanılarak firmaların kendilerini iyileştirme miktarlarını tespit edilebilecek matematiksel bir model Denklem (8)'de ki gibi oluşturulup, KTGO ile de optimize edilmiştir.

$\max f\left(x_{1}, x_{2}, \ldots, x_{11}\right)=0.255 x_{1}+0.163 x_{2}+0.124 x_{3}+0.047 x_{4}+0.027 x_{5}+0.026 x_{6}+0.026 x_{7}+0.107 x_{8}+$ $0.086 x_{9}+0.065 x_{10}+0.065 x_{11}$

Denklem (8)'de yer alan ${ }^{x x}$ 'ler belirlenen kriterleri ifade etmektedir. Firmaların bir alanda iyileşme miktarlarının gerçeği yansıtması ve diğer firmaların ortalama değerlerinin altında kalmaması için optimizasyon problemi için amaç fonksiyonunun kısıtları Denklem (9)'da ki gibi belirlenmiştir. 


$$
\begin{array}{ll}
\text { s.t. } & x_{3}+x_{5}+x_{6}+x_{7} \geq 28.875 \\
& \frac{x_{1}+x_{2}+x_{4}}{3} \leq \frac{x_{8}+x_{9}+x_{10}+x_{11}}{4}
\end{array}
$$

Kısıtlar arasında yer alan 28.875 değeri, $x_{3}+x_{5}+x_{6}+x_{7}$ kriterlerinin her bir sütun toplamının 8 tedarikçi fïmaya ortalamasına göre belirlenmiştir. İlgili kısıtlar belirlenirken kriterler aralarındaki uyum durumuna göre kategorilere ayrılmıştır. “Ürünün kalitesi, defosuz ürün miktarı ve paketleme yeteneği“ birinci kategori, "ürün fiyat uygunluğu, iskonto miktarı, ödeme vadesi ve ödeme şekli” ikinci kategori, "zamanında teslimat, iletişim kolaylığı, sorunlara yaklaşım ve şikâyet politikaları" da üçüncü kategoriyi oluşturmaktadır. Ayrıca tedarikçi bir firmanın belirlenen kriterlerde yapacağı değişimin 2'den küçük olması sınır değer olarak önerilmektedir. Bunun sebebi de işletmede yapılacak büyük değişikliklerin devasa maliyetlere neden olmasıdır. Burada değişimi asıl isteyen tedarikçi değil mal sattığı perakendeci olup büyük değişiklikler yerine daha makul ve kolay değişiklikleri uygulama eğiliminde olduğundan, kriter değişiminin en fazla 2 olması daha uygundur.

TOPSIS yöntemi kullanılarak bulunan en iyi tedarikçi olan Firma H ile diğer tedarikçilerin kıyaslaması KTGO ile elde edilen sonuçlara göre yapılmış olup tedarikçiler için elde edilen en uygun değerler Tablo 7'de görülmektedir.

Tablo 7

\begin{tabular}{|c|c|c|c|c|c|c|c|}
\hline KRİTERLER & Firma A & Firma B & Firma C & Firma D & Firma E & Firma $\mathbf{F}$ & Firma G \\
\hline Ürünün Kalitesi & 8,23 & 8,53 & 8,27 & 9,02 & 10,00 & 8,31 & 10,00 \\
\hline Defosuz Ürün Miktarı & 8,03 & 7,26 & 7,03 & 8,00 & 9,00 & 8,09 & 9,00 \\
\hline Zamanında Teslimat & 7,95 & 7,94 & 5,08 & 8,03 & 9,00 & 5,41 & 9,00 \\
\hline Paketleme Yeteneği & 7,00 & 8,03 & 7,29 & 8,03 & 9,00 & 7,08 & 9,00 \\
\hline İletişim Kolaylığı & 8,02 & 7,04 & 8,05 & 8,02 & 9,00 & 8,07 & 9,00 \\
\hline Sorunlara Yaklaşım & 8,01 & 7,08 & 8,00 & 8,02 & 9,00 & 8,15 & 9,00 \\
\hline Şikayet Politikaları & 8,00 & 7,06 & 8,03 & 7,00 & 9,00 & 8,06 & 9,00 \\
\hline Ürün-Fiyat Uygunluğu & 5,06 & 7,00 & 7,01 & 4,00 & 9,00 & 7,08 & 9,00 \\
\hline İskonto Miktarı & 7,06 & 5,00 & 8,01 & 6,12 & 9,00 & 7,14 & 9,00 \\
\hline Ödeme Vadesi & 5,02 & 6,01 & 7,01 & 4,03 & 8,00 & 6,05 & 8,00 \\
\hline Ödeme Şekli & 6,50 & 6,00 & 8,00 & 6,66 & 9,00 & 6,43 & 9,00 \\
\hline
\end{tabular}

KTGO ile elde edilen sonuçlar

Tablo 7'de KTGO ile elde edilen sonuçlar ile Tablo 4'teki değerler karşılaştırıldığında; Firma A için "zamanında teslimat" kriterini neredeyse 1 puan geliştirmesi gerektiği ve en büyük yatırımı bu alana yapması sonucuna ulaşılmıştır. Sonrasında ise "ödeme şekli” kriterine yatırım yapması önerilmiştir. Diğer kriterlerden olan "paketleme yeteneğì" ve "şikayet politikaları" kriterlerinde herhangi bir iyileştirmeye ihtiyaç duyulmamıştır. Diğer kriterler için de küçük miktarlarda yatırımlar yapmalıdır. Firma B için ise en fazla yatırım "zamanında teslimat” kriterine yapılmalı olup, bunu “ürünün kalitesi” kriteri takip etmektedir. “ürün fiyat uygunluğu”, “iskonto miktarı” ve “ödeme şekli” kriterlerinde bir değişim söz konusu değildir ancak diğer kriterlere de yatırım yapılması gerekmektedir. Firma C'ye bakıldığında “ürünün kalitesi” 1 puandan fazla arttırılmalıdır. "Sorunlara yaklaşım” ve “ödeme şekli” kriterlerinin arttırılmasına gerek duyulmamıştır. Geri kalan kriterlerde az miktarda değişime gidilmesi önerilmiştir. Firma D’nin ise “ödeme şekli” kriterini 1.5 puandan fazla arttırması ve "şikâyet politikaları” ile “ürün fiyat uygunluğu” kriterlerinde herhangi bir değişime gitmemesi önerilmiştir. Diğer kriterler içinde küçük yatırımlar yapılmalıdır. Firma E için ise, KTGO yöntemi yatırım yapılacak kriterlerde maksimum değerleri önermektedir. Sınır değer 2 olarak belirlenmesine rağmen bu firma için 2 puanlık bir yatırım yetersiz kalmaktadır. Daha köklü değişikliklere gidilmesi ilgili firma için önerilmektedir. Firma F'ye bakıldığında ise bir kritere büyük miktarda yatırım yapmak yerine tüm kriterlere küçük miktarlarda yatırım yapılması önerilmiştir. Firma G’nin de Firma E gibi maksimum değerlerde yatırımlar yapması gerekip bu iki firma için küçük değişimler istenilen faydayı sağlayamamaktadır.

\section{TARTIŞMA ve SONUÇ}

Türkiye'de perakende satış yapan işletmelerin sayısı gün geçtikçe artış göstermektedir. Bu durum tedarikçi fïrmalar için zorlu bir rekabet ortamı yaratmaktadır. Bundan dolayı tedarikçi firmalar perakendeci işletmelerin isteklerini kolay kolay reddedemezler. Perakendeci işletmeler bu durumun farkında olmasına rağmen tedarikçisinden de ürünü maliyetine satmasını isteyemezler. Bunun için iki tarafın da tatmin olabileceği bir orta yol bulunup ilgili istekler makul ölçüde olmalıdır. 
Bu çalışmada hem işletmenin hem de tedarikçinin optimum kâr elde edebilmesi için en uygun çözümü içeren, tedarikçilerin yatırım yapması gereken alanların optimizasyonu gerçekleştirilmiştir. İlgili çalışmada, Burdur ilinde perakende çalışan bir işletme ele alınmış olup bu işletmenin tedarikçilerinin yatırım alanları ve oranları bulunmuştur. Çalışmanın sonucunda ağırlığı en yüksek olan Firma H’nin muadili olarak Firma D gösterilebilmektedir. Ürün portföyü en geniş olan Firma D ele alınan tüm tedarikçilerin muadili konumundadır. A, B, C, D, G firmaları birbirinin muadili iken E, D ve F firmaları da kendi aralarında birbirinin muadilidir Önerilen matematiksel model ve optimizasyon ile tedarikçiler kendilerini ne ölçüde geliştirmeleri gerektiğini belirleyebileceklerdir. Bu durum sonucunda hem tedarikçi firmalar hem de yönlendiren işletmeler en optimum kazancı elde etmiş olacaklardır. Tedarikçisini değiştirmek istemeyen işletmelerin önerilen modeli kullanarak tedarikçilerini geliştirmeleri önerilmektedir. Tedarikçilere ise ağırlığı en yüksek olan ‘ürün kalitesi’ konusunda kendilerini geliştirmeleri önerilmektedir.

Günay ve Ünal (2016)'a ait bir telekomünikasyon şirketinin hizmet alımı yaptığı dört tedarikçi firmanın sıralaması çalışmasında elde edilen ağırlığı en yüksek olan kriter "kalite" kriteri olarak bulunmuş olup, bu da bu çalışmada elde edilen sonuçla paralellik göstermektedir.

Çalışmanın kısıtı olarak, geliştirilen modelin tek bir işletme için oluşturulmuş olması gösterilebilir. Diğer firmaların modeli kullanabilmeleri kendi belirleyecekleri tedarikçilerini ve gerekli gördükleri kriterleri ele alarak modeli güncellemeleri gerekmektedir. İleriki çalışmalarda belirli bir sektörde yer alan birçok firma ele alınarak ortak bir model geliştirilebilir.

Hakem Değerlendirmesi: Dış bağımsız.

Çıar Catıșması: Yazarlar çıkar çatıșması bildirmemiștir

Finansal Destek: Yazarlar bu çalışma için finansal destek almadığını beyan etmiştir.

Yazar Katkıları: Çalışma Konsepti/Tasarım- C.O., İ.P., M.Ş.Ç., Ö.Ç.B.; Veri Toplama- C.O.; Veri Analizi/Yorumlama-C.O., İ.P., M.Ş.Ç., Ö.Ç.B.; Yazı Taslağı- C.O., Ö.Ç.B.; İçeriğin Eleştirel İncelemesi-C.O., İ.P., M.Ş.Ç., Ö.Ç.B.; Son Onay ve Sorumluluk- C.O., İ.P., M.Ş.Ç., Ö.Ç.B.

Peer-review: Externally peer-reviewed.

Conflict of Interest: The authors have no conflict of interest to declare.

Grant Support: The authors declared that this study has received no financial support.

Author Contributions: Conception/Design of Study- C.O., İ.P., M.Ş.Ç., Ö.Ç.B.; Data Acquisition- C.O.; Data Analysis/Interpretation- C.O., İ.P., M.Ş.Ç., Ö.Ç.B.; Drafting Manuscript- C.O., Ö.Ç.B.; Critical Revision of Manuscript- C.O., İ.P., M.Ş.Ç., Ö.Ç.B.;Final Approval and Accountability- C.O., İ.P., M.Ş.Ç., Ö.Ç.B.

\section{Kaynaklar/References}

Akbel, M. ve Kahraman, H.T. (2020). Çok Amaçlı Meta-Sezgisel Optimizasyon Algoritmalarının Performanslarının Karşılaştırılması. Mühendislik Bilimleri ve Tasarım Dergisi, 8(5), 185-199.

Atalay, M., \& Çelik, E. (2017). Büyük Veri Analizinde Yapay Zeka ve Makine Öğrenmesi Uygulamaları. Mehmet Akif Ersoy Üniversitesi Sosyal Bilimler Enstitüsü Dergisi, 9(22), 155-172.

Avcı, T. ve Çınaroğlu, E. (2018). AHP Temelli TOPSIS Yaklaşımı İle Havayolu İşletmelerinin Finansal Performans Değerlemesi. C. ̈̈. İktisadi ve İdari Bilimler Dergisi, 19(1), 316-335.

Chai, J., Liu, J. N., \& Ngai, E. W. (2013). Application of decision-making techniques in supplier selection: A systematic review of literature. Expert systems with applications, 40(10), 3872-3885.

Çakmak, Z., Uzgören, N., \& Keçek, G. (2005). Kümeleme Analizi Teknikleri ile İllerin Kültürel Yapılarına Göre Sınıflandırılması ve Değişimlerinin İncelenmesi. Dumlupınar Üniversitesi Sosyal Bilimler Dergisi, 12, 15-36.

Çunkaş M. (2004). Elektrik Makinalarının Genetik Algoritmayla Optimizasyonu. Doktora Tezi, Selçuk Üniversitesi, Fen Bilimleri Enstitüsü, Konya.

Dumanoğlu, S., \& Ergül, N. (2010). İMKB’de İşlem Gören Teknoloji Şirketlerinin Mali Performans Ölçümü. Muhasebe ve Finansman Dergisi, 48, 101-111.

Ertuğrul, İ. \& Özçil, A. (2014), “Çok Kriterli Karar Vermede TOPSIS ve VIKOR Yöntemleriyle Klima Seçimi”, Çankırı Karatekin Üniversitesi İktisadi ve İdari Bilimler Fakültesi Dergisi, 4(1), 267-282.

Fashoto, S. G., Akinnuwesi, B., Owolabi, O., \& Adelekan, D. (2016). Decision support model for supplier selection in healthcare service delivery using analytical hierarchy process and artificial neural network. African journal of business Management, 10(9), $209-232$.

Fazlollahtabar, H., Mahdavi, I., Ashoori, M.T., Kaviani, S., Mahdavi-Amiri, N., (2011). A multi-objective decision-making process of supplier selection and order allocation for multi-period scheduling in an electronic market. The International Journal of Advanced Manufacturing Technology, 52, 1039-1052.

Fırat, H., \& Alpaslan, N. (2019). Sezgisel Algoritmalar Kullanılarak İki Boyutlu Dikdörtgen Şerit Paketleme Probleminin Çözümü. Avrupa Bilim ve Teknoloji Dergisi, (17), 315-322. 
Günay, Z., \& Ünal, Ö. F. (2016). Ahp-Topsıs Yöntemi İle Tedarikçi Seçimi (Bir telekomünikasyon şirketi örneği). PESA Uluslararası Sosyal Araştırmalar Dergisi, 2(1), 37-53.

Hwang, C. L., \& Yoon, K. (1981). Methods for multiple attribute decision making. In Multiple attribute decision making. Springer, Berlin, Heidelberg, 58-191.

Kaya Keleş, M. ve Keleş, A. E. (2017). Veri Madenciliği Uygulamalarının ve Sezgisel Optimizasyon Algoritmalarının Yapım Yönetimindeki Yeri. Çukurova Üniversiesi Mühendislik Mimarllk Fakültesi Dergisi, 32(1), 235-242.

Kerkhoff, E. (2018). Çok Kriterli Karar Verme Yöntemleriyle Tedarikçi Seçimi, Yayınlanmamış Yüksek Lisans Tezi, İstanbul Ticaret Üniversitesi Sosyal Bilimler Enstitüsü, İstanbul.

Niranjan, T., Singaravel, B., \& Raju, S. S. (2021). Integrated Fuzzy Criteria Evaluation with Metaheuristic Optimization for Green Supplier Selection and Order Allocation. In IOP Conference Series: Materials Science and Engineering, 1057(1), 012074.

Okwu, M. O., \& Tartibu, L. K. (2020). Sustainable supplier selection in the retail industry: A TOPSIS-and ANFIS-based evaluating methodology. International Journal of Engineering Business Management, 12, 1-14.

Özçakar, N., \& Demir, H.H. (2011). Bulanık TOPSIS Yöntemiyle Tedarikçi Seçimi. İstanbul Üniversitesi Işsletme Fakültesi Işsletme İktisadi Enstitüsü Yönetim Dergisi, 22(69), 25-44.

Özçelik, T. Ö., \& Gündüz, G. (2019). Sezgisel Algoritmaları Kullanarak Raf Optimizasyonu Çalışması ve Bir Yazılım Uygulaması. Avrupa Bilim ve Teknoloji Dergisi, (16), 977-982.

Özdemir, A. (2007). Tedarikçi Seçiminde Karar Modelleri ve Bir Uygulama Denemesi. Doktora Tezi, Uludağ Üniversitesi Sosyal Bilimler Enstitüsü, 158s., Eskişehir.

Öztürk, D. (2019). Selection of Suppliers Using AHP and TOPSIS Methods: An Application in the Ready-Made Clothing Sector. Journal of Textiles and Engineer, 26(115), 299-308.

Pençe, İ., Tarhan, L., \& Çetinkaya Bozkurt, Ö. (2017). Türk Eğitim Vakfı Bursu Verilecek Uygun Adayların AHP ve TOPSIS Yöntemi Kullanılarak Belirlenmesi: Mehmet Akif Ersoy Üniversitesi Eğitim Fakültesi Örneği. Mehmet Akif Ersoy Üniversitesi Uygulamalı Bilimler Dergisi, 1(1), $37-49$.

Pençe, İ., Şişeci Çesmeli, M., Senel, F. A., \& Cetisli, B. (2016). A new unconstrained global optimization method based on clustering and parabolic approximation. Expert Systems with Applications, 55, 493-507.

Pramanik, D., Haldar, A., Mondal, S. C., Naskar, S. K., \& Ray, A. (2017). Resilient supplier selection using AHP-TOPSIS-QFD under a fuzzy environment. International Journal of Management Science and Engineering Management, 12(1), 45-54.

Saaty, T.L., \& Özdemir, M.S. (2003). Negative Priorities in the Analytic Hierarchy Process. Mathematical and Computer Modelling, 37(9-10), 1063-1075.

Saaty, T.L. (1980). The Analytic Hierarchy Process. McGraw-Hill International Book Company, New York.

Shyjith, K., Ilangkumaran, M., \& Kumanan, S., (2008). Multi-criteria Decision-making Aaproach to Evaluate Optimum Maintenance Strategy in Textile Industry. Journal of Quality in Maintenance Engineering, 14(4), 375-386.

Supçiller, A., \& Çapraz, O. (2011). AHP-TOPSIS Yöntemine Dayalı Tedarikçi Seçimi Uygulaması. İstanbul Üniversitesi İktisat Fakültesi Ekonometri ve Istatistik Dergisi, 13, 1-22.

Şahin, Y. ve Akyer, H. (2011). Ülke Kaynaklarının Verimli Kullanımı: 4×4 Arama ve Kurtarma Aracı Seçiminde AHS ve TOPSIS Yöntemlerinin Uygulanması. Süleyman Demirel Üniversitesi Vizyoner Dergisi, 3(5), 72-87.

Tempelmeier, H. (2002). A simple heuristic for dynamic order sizing and supplier selection with time-varying data. Production and Operations Management, 11(4), 499-515.

Vatansever, K. (2013). Tedarikçi Seçim Kararlarında Bulanık TOPSIS Yönteminin Kullanımı ve Bir Uygulama. Anadolu Üniversitesi Sosyal Bilimler Dergisi, 13(3), 155-168.

Wang, J.-W., Cheng, C.-H., Kun-Cheng, H., (2009). Fuzzy hierarchical TOPSIS for supplier selection. Applied Soft Computing, 9, $377-386$.

Yayar, R., \& Baykara, H.V. (2012). TOPSIS Yöntemi İle Katılım Bankalarının Etkinliği ve Verimliliği Üzerine Bir Uygulama. Business and Economics Research Journal, 3(4), 21-42. 
